\title{
Editorial: A critical life course stage
}

\author{
John Bynner Executive Editor
}

This issue of the journal displays the variety and richness of the submissions the publication receives in the field of longitudinal and life course study.

We start with a special section on transitions in the third decade of life - the 20s - guest edited by Marlis Buchman (Zurich), Heiki Solga (Berlin) and Tina Malti (Toronto). The section comprises four papers introduced by Marlis Buchmann and Heike Solga, with authors spanning Canada, USA, Finland, Germany, UK, Switzerland and China. We then move to two individual papers. The first is on changes in early transition from school to work in England. The second is a methodological paper on the biasing effects brought about by selection processes in sample attrition in Swedish longitudinal study.

The twin effects of secular change and heterogeneity of experience from age 20 are central to this stage of the life course, as reflected in the developmental transitions that take place. Many, such as from education to work, are completed during this period, if not before, while others such as partnership/marriage, have yet to occur or are just beginning. The key point is that the transition's impact on the direction the life course takes will be felt across the whole of the life span.

The biological processes in maturation set the physical parameters for young adulthood and the stages that follow of middle life through the 30s, $40 \mathrm{~s}$ and increasingly as life extends, the 50s. They may also signal the beginnings of closure with the winding down of physical prowess and the onset of old age.

I was fascinated in reading a few days ago the ages of the players in UK Premier Division football clubs. The average age for every single one of them was 27 or 28 and those top clubs with 28 -year-olds were already identifying them for potential transfer to other less prestigious clubs and then retirement. Seen from this perspective the huge salaries top players earn are less surprising - part of a life course with a highly restricted window of opportunity in the 20s through which to build a secure future or progress potentially to nothing.

But biology is only one part of the story. In the current era, we are witnessing transformation of institutions and experience in such life course domains as employment, with impact on all the others - ranging through partnership and marriage, housing, social life, political engagement, crime, mental and physical health and, of course, massive movement of people.

This is while technological development transforms society at an ever accelerating rate and automation from artificial intelligence to robotics takes over what was once defined as human work. The misconceived idea (in my view) of the 'standardised' life course, not to mention the stratification that goes with it, takes even more of a battering. The occupational and labour market certainties of the past give way to the casualisation of labour, the move to part-time contracts and, most damaging to personal security of all, the zerohours contract. These employment forms have wider implications reflected by a new sub-stratum cutting across the skills-based socioeconomic statuses of the past - the 'precariat'. For these 2030 year olds the collective organisation and protection supplied in the past by, for example, trade unions are largely non-existent.

Unlike the experience of past centuries, as the international range of our contributors affirms, these processes are operating on an ever-more global scale, universalising labour market experience and driving ever widening inequality. They are also accompanied by diminishing effectiveness of national governments to control it.

And it is not only employment as we knew it that is disappearing. There is a mediating effect of labour market changes on other life course domains such as family formation and especially housing where the prospects of security through home ownership, without substantial parental subsidy, are rapidly disappearing. The golden age of affluence and autonomy has been replaced since the banking collapse of $2007 / 8$ by that of austerity and extended dependency, making the rich very much richer and the poor relatively very much poorer.

We hear from Oxfam that the 62 people whose collective wealth, in January 2016, exceeded that of half the world's population has now reduced to 8 . 
Yet at the same time the ingenuity of such ideas as the 'Citizen Wage' and the passion of the movements to promote it suggests that, as ever, human striving for individual and collective survival will prevail.

The papers in this edition's special section pay particular regard to these challenging aspects of young adulthood in the contemporary world. The role of psycho-social resources is the centre of attention coupled with other resources available to the new generation in making their transitions in particular domains. The focus is first on the role of the moral antecedents of young adults' attitudes to inequality, then on life satisfaction, education and occupation, then socioeconomic resources and individual agency. Finally, a first for the journal completes the picture - an exploration of the consequences of exposure to the criminal justice system for health.

The individual papers in this issue extend the story, focusing first on historical change: cohort shifts in relation to the key life course transition from school to work. Finally, we learn that our ability to understand these effects goes only as far as the representativeness of our sample data and the robustness of our analyses can take us, because of the biasing effects of different types of 'selective' sample loss. Attrition - described as the 'Achilles heel' of longitudinal research - takes on even more significance at a time of massive social, economic and technological change.

Congratulations to the authors in drawing our attention to these challenges to the conventional wisdom about the world as it used to be and what it is likely to become. There was never a time when longitudinal and life course study and platforms communicating its findings, such as LLCS, were more needed. 